\title{
Small loan schemes: the experience of Ethiopia
}

\author{
MONTBAINOR ABERA \& MELESSEW SHANKO \\ German Leprosy Relief Association, PO Box 5033, Addis Ababa, \\ Ethiopia
}

\section{Introduction}

Leprosy is a medico-social problem and more than a disease. Statistics indicate that the disease, as a medical problem, has been decreasing steadily world wide since the advent of multi-drug therapy (MDT) in the early 1980s. However, the social dimensions of the disease in terms of stigma, poverty, disabilities and deformities, loss of self-respect and dignity have continued to constitute a major social problem in many developing countries.

Until the 1970s, rehabilitation in Ethiopia was merely considered as an act of charity. It was undertaken by religious persons and institutions. Throughout the 1940s and 1950s patients were kept within the leprosy hospitals compounds where they were provided with shelter, food, and sometimes clothing in addition to medical treatment. In Addis Ababa, a volunteer (also a missionary) established a sheltered workshop in 1950 for 250 persons. The German Leprosy Relief Association (GLRA) established the Relief Center Bisidimo for treatment and rehabilitation of patients in 1958. A group of volunteers from Haile Sellassie I University ( now named Addis Ababa University) initiated a resettlement and rehabilitation project for 80 displaced leprosy-afflicted families. In the north (Boru Meda) the Society of International Missionaries (SIM) used to provide rehabilitation services for patients; a sheltered workshop that has accommodated 62 households was erected at the end of the 1960s. The American Missionaries had been undertaking rehabilitation activities in Kuyera, near Shashemene, $240 \mathrm{~km}$ south of Addis Ababa; a total of about 570 families were resettled around the hospital to carry out farming on individual bases in 1950 and 1966.

Generally however, the pre-1970 rehabilitation efforts were all institutional. In the early and mid-1970s, approaches had incorporated some of the features of institutional and community based rehabilitation (CBR).

In a country where there is no clear social policy, rehabilitation takes many forms and up to 1990, rehabilitation in Ethiopia had been sporadic. Neither the National Leprosy Control Programme ( NLCP) nor the donor agency (GLRA) had a clear policy on rehabilitation; they were concerned with the medical aspects of the problem. In 1988, GLRA in collaboration with NLCP set up a Social Rehabilitation Department with in the NLCP, to coordinate and promote rehabilitation activities. Since 1999 the government of Ethiopia has adopted a social policy (preventive, developmental and rehabilitative).

Correspondence to: M Abera (e-mail: GLRA@telecom.net.et, Tel: +251 171 12 98, Fax: +251 17127 99) 
In 1990 the Social Rehabilitation Department, GLRA-Ethiopia, made a study of the conventional rehabilitation centres, sheltered workshops and colonies, which comprised about 48,000 people affected by leprosy. Most of these communities/rehabilitation centres could not be self-supportive. A 3-year pilot programme was adopted in selected areas of the country using the CBR approach.

The aim of the small loan pilot project was to promote full participation and enhance integration of those affected into mainstream community life in their respective communities through alleviation of their social and economic problems that made such an involvement difficult hitherto. A revolving fund was allocated for the project to provide interest free loans to help set up new self-identified income generation (self-employment) facility or to maintain and improve existing ones.

At the end of the project period, December 1997, a study was conducted to evaluate the performance, and impacts of the pilot project on the beneficiaries. Specifically, the objectives of the study were to:

- Identify weakness and strengths of the small loan approach and its components in social and economic rehabilitation for people affected by leprosy.

- Produce information necessary for preparation of a guidance manual for implementation of the program in the future.

- Provide information to others interested in micro-credit schemes.

- Assist in development and improvement of project's internal monitoring and evaluation system.

- Set out recommendations on how best the programme can achieve its stated objectives during its subsequent phase(s).

Based on the outcomes and recommendations of the evaluation study, the programme has been launched in full in various other parts of the country since 1998. This paper presents the results of the evaluation study of the pilot project and the status of the programme in Ethiopia.

\section{Materials and methods}

The evaluation study was conducted in Gondar, Gojjam, Wollo and Addis Ababa programme areas. A sample of 36 beneficiaries/clients was drawn from a total population of 168 (beneficiaries) using simple random sampling technique. All questionnaires were administered to individual client by the researchers. This gave the researchers the chance to observe and communicate personally with respondents, their family and other relevant community members and leprosy control and programme staff, all of whom are involved in the programme.

A structured interview composed of open and close questions, case studies, participation observation, quantitative notes and reports documented by the program were used as data gathering tools to generate both quantitative and qualitative data.

The questionnaires were thoroughly examined and commented on by the rehabilitation officers and pre-tested on a randomly selected other beneficiaries. As part of its internal monitoring and follow-up mechanism, the programme holder had a database on the pilot project in the form of quarterly review meetings, annual progress reports and individual beneficiary files. Individual beneficiary files at project site were reviewed to obtain a more detailed information on frequency and helpfulness of follow up visits, level of technical assistance provided and level of loan repayment collection. The data for the assessment of the 
status of the programme for the years 1998 and 1999 were obtained from quarterly and annual review meetings and reports.

\section{Results}

The sample of 36 beneficiaries included 22 men and 14 women, with two aged more than 60 years. Two-thirds of the clients were married while the remaining one-third were equally distributed among separated/divorced, widowed and single.

Seventy-eight percent of the clients had grade II disability and the remaining $22 \%$ had no visible disabilities.

As a result of the project, a change in the employment pattern of the study population was observed. The project created self-employment opportunity for some, others were engaged in new trades abandoning the previous ones, while still others expanded the existing trades.

There were a few cases where the loan taken to finance income-generating activity was spent totally or partially on non-income generation activity such like purchasing clothes and acquiring urban land from local authorities for house construction.

Respondents were asked to evaluate their economic and living conditions, to assess the attitude of their family and community towards them by comparing the situations before and after their involvement in the project. Savings, income, food intake, clothing and housing had improved for most clients. This implied that the pilot project had helped to improve the economic and living conditions of the study population as perceived by the respondents. It was observed that out of 22 clients who had their own 'house', nearly half had improved them either by renovating or reconstructing from the income accrued.

The pilot project had set out a fairly elaborate loan security procedures and repayment schedule. Analysis of the degree of compliance of the clients (loanees) to the terms and conditions set out for the loan scheme indicated that the majority $(61 \%)$ always made regular repayments. A few clients (17\%) showed some 'irregularities' in their repayment schedule, but in the strict sense, it was hard to label them as 'irregulars', because most updated their repayment status by making all their overdue payments at one time or during the preceding periods. The overall repayment rate was $78 \%$. Assessment of follow-up reports and beneficiary files showed that all the defaulters were those who received a loan during the first year of the project.

SOCIAL AND ATTITUDINAL ASPECTS

As regards the attitudinal change and social relationships, over $86 \%(31 / 36)$ of the study population reported that attitudes of their community and family members towards them had improved considerably. This was expressed in terms of development and improvement of social relationships, membership in funeral societies and respect and recognition among their neighbours and family members.

\section{Discussion}

Apart from its (the loan component) contribution to development and strengthening of the local micro-economy, the pilot project has brought about a number of positive impacts on the 
majority of the study population. The major impacts could be classified as economic, social and attitudinal.

Given the high degree of physical disabilities, lack of experience in running business, and the social and economic environment the clients operate, the repayment rate of $78 \%$ was generally high and encouraging.

Based on the evaluation outcome and recommendation, a 5-year project (1998-2002) was prepared and submitted to GLRA-HQ for approval. The programme at full scale started in 1998.

Flexibility of project staff on loan repayment collection/schedules was important. The relatively high repayment rate of loans was not only because the clients were successful in their self-employment, but there was good understanding between the staff and the clients. The staff made regular follow-up visits, gave advice to their clients and were flexible on repayment collection schedules should a client have a problem. They gave more consideration to the client's problem than to the financial aspects of the programme.

In a loan scheme for leprosy affected people with some socio-economic problems, repayment rate alone should not be assumed as a measure of success of the rehabilitation programme, since financial assistance alone could not bring a change in clients way of life.

Inclusion of other people with non-leprosy disabilities, who live close to and share the same social and economic deprivation with leprosy affected people will facilitate the change in attitude both among the non-leprosy disabled and in the community.

Timely follow-up and advice is indispensable for clients who are engaged in new trade and have no family support. Gradual transfer of loan clients to the formal financial institutions (micro-finance enterprises) is the ultimate aim of the interest-free loan scheme. Otherwise, soft loans may create a new form of dependency on the beneficiaries, should the loan continue for several phases. It will also create jealousy among community members where beneficiaries live. 